\title{
Processing of low grade tungsten ore concentrates by hydrometallurgical route with particular reference to India
}

Keywords. Low grade concentrate; pressure leaching; purification of concentrate and leach solution; solvent extraction; APT; crystallization.

\section{Introduction}

Tungsten is widely used for diverse applications that include cutting tools, ferrotungsten for alloy steel, electric and electronic components and armament related products. India's requirement of this metal is around 1500 tonnes per annum and a significant portion is used for cutting tools. In view of its strategic importance the demand is poised for a steep rise to about 3000 tonnes per annum by the year 2000 . Tungsten based industries use wolframite or scheelite of appropriate grade as primary source of tungsten, though a minor portion of the captive scrap is also recycled.

In India tungsten occurs both in the form of wolframite and scheelite at various places such as Degana, Balda, Devakabera in Rajasthan, Almora in UP. Agargaon, Kuhikhobna in Maharashtra, Bankura in West Bengal and Burugubanda in A.P. The available grades of ores analyse between 0.04 to $0.2 \% \mathrm{WO}_{3}$ and most of the grade falls below $0.1 \% \mathrm{WO}_{3}$. The concentrate for commercial use generally required is above $60 \% \mathrm{WO}_{3}$ while for special purposes a higher grade of $+65 \% \mathrm{WO}_{3}$ is needed. This requires an enrichment of $\mathrm{WO}_{3}$ between 300 to 1600 times. Even after such enrichment by physical beneficiation methods, the end product does not meet the desired specification in terms of purity and grade, because most of the tungsten minerals are found to be 
intimately mixed with undesirable elements like tin, molybdenum, phosphorus, arsenic, sulphur and other base metals.

As regards processing, it has been found more profitable to produce low grade concentrates with higher recovery of tungsten from the lean ores. When such low grade concentrate is converted to an intermediate product such as ammonium paratungstate (APT), better plant economy results. Therefore, an appropriate technology involving conversion of low grade concentrate to APT by aqueous processing should be developed to suit the Indian conditions, where, by and large deposits are of low grade nature.

This paper first presents a review of the hydrometallurgical processes developed or in developmental stage to recover tungsten values from low grade scheelite and wolframite concentrates. It then gives a brief account of the studies undertaken at NML to purify and recover the tungsten from a number of samples, such as table concentrate $\left(66 \% \mathrm{WO}_{3}\right)$, jig concentrate $\left(4.6 \% \mathrm{WO}_{3}\right)$, obtained from RSTDC, Rajasthan and middlings $\left(18-20 \% \mathrm{WO}_{3}\right)$ generated during physical beneficiation process at NML. These studies include development of process details to eliminate the impurities such as silica and sulphur from the table concentrate, and to recover tungsten as ammonium paratungstate (APT) from low grade jig concentrates by adopting the pressure leaching and solvent-extraction.

\section{Processing of tungsten ores/concentrates - A review}

There are two main primary sources of tungsten viz scheelite $\left(\mathrm{CaWO}_{3}\right)$ and wolframite (FeMn) $\mathrm{WO}_{4}$ from which metal is extracted. The $\mathrm{WO}_{3}$ content in the ore varies from 0.1 to $0.5 \%$. The ores form veins in quartzites or occur at the interface between granite and limestone. The ore is also associated with impurities such as tin, molybdenum, bismuth, arsenic, copper, sulphur etc. These impurities can not be removed by physical beneficiation methods and can be eliminated by the chemical treatment such as roasting, acid leaching etc. Because of the high meiting point of tungsten, the processes are based on hydrometallurgical rather than pyrometallurgical methods. While a large number of processes have been developed for decomposing the tungsten ore and purifying the resultant compounds, only a few have been adopted into practice. Choice of the ore decomposition depends on both, the type and grade of the concentrate and determines the options available for subsequent steps. In general the hydrometallurgical process developed consists of pretreatment of ores/concentrates, leaching under pressure with acid/alkali, purification followed by solvent extraction/precipitation and crystallization to produce ammonium paratungstate.

\subsection{Pretreatment of concentrates}

During physical beneficiation step, the impurities associated with scheelite and wolframite are not completely removed. Further, the concentrates produced are often contaminated with organic reagents causing excessive foaming during alkali leaching step. Roasting of the concentrate at high temperature with excess air is an effective method for removing impurities like sulphur, arsenic and organic contaminants. Yih and Wang (1979) reported that the roasting of low grade scheelite at $600^{\circ} \mathrm{C}$ for $4 \mathrm{~h}$ in air completely eliminated organic carbon and also reduced arsenic from $300 \mathrm{ppm}$ to 
$15 \mathrm{ppm}$. However, in case of wolframite the concentrate is roasted at $800^{\circ} \mathrm{C}$ in air for 2-4 $\mathrm{h}$ for the removal of sulphur and arsenic.

\subsection{Decomposition of ores/concentrates}

2.2a Leaching of scheelite concentrate: Most scheelite ores have average $\mathrm{WO}_{3}$ content less than one percent and are concentrated to $15-70 \% \mathrm{WO}_{3}$. The concentrate is then leached by acid $(\mathrm{HCl})$ or alkali $\left(\mathrm{Na}_{2} \mathrm{CO}_{3} / \mathrm{NaOH}\right)$. Acid leaching is normally used for higher grade concentrates, whereas alkali leaching is applicable to lower grade concentrates. Hamilton (1918) developed a process to treat low grade scheelite concentrate based on the selective leaching with aqueous soda ash solution. The process was first used on a commercial scale by Union Carbide at Bishop, California, where scheelite concentrate analysing $10-20 \% \mathrm{WO}_{3}$ have been treated for the past four decades. The process operates at $190-225^{\circ} \mathrm{C}$, for 1 to $4 \mathrm{~h}$ duration using 110 to $210 \mathrm{~g} / \mathrm{l}$ $\mathrm{Na}_{2} \mathrm{CO}_{3}$ solution depending on feed of the grade. Similar plants are operating in Austria, Korea, Germany and Russia.

Maslenitsky and Perlov (1960) reported the leaching of scheelite and rough tungsten concentrate and middlings containing 1 to $24 \% \mathrm{WO}_{3}$. The recovery of tungsten in solution ranged from 94 to $99 \%$ whereas soda consumption varied from 1.5 to $4.0 \mathrm{~kg} / \mathrm{kg}$ of $\mathrm{WO}_{3}$ in the feed. However, in some cases where the $\mathrm{WO}_{3}$ content was not more than $3 \%$ and gangue was more, soda consumption was $5-7 \mathrm{~kg} / \mathrm{kg}$ of $\mathrm{WO}_{3}$. It has also been reported that variation of initial concentration of sodium carbonate up to $230 \mathrm{~g} / 1$ has no effect on recovery of tungsten from scheelite but, above this concentration recovery drops. This is mainly due to the formation of insoluble double carbonate of sodium and calcium $\left(\mathrm{Na}_{2} \mathrm{CO}_{3} \cdot \mathrm{CaCO}\right)$. Queneau et al (1981) observed similar results during leaching of the scheelite concentrate analysing $13-30 \% \mathrm{WO}_{3}$. A similar phenomenon, reported by Bhosale et al (1990), occurs in case of wolframite when it is leached with sodium carbonate. The iron and manganese carbonate formed during leaching decomposed into the corresponding oxides and carbon dioxide, the carbondioxide leads to the building up of biocarbonate ions in the leach solution, thus inhibiting the efficiency of leaching. Queneau and Cooke (1969) studied the leaching rate of scheelite with sodium carbonate and suggested a method for removing the calcite film from scheelite particles. It was demonstrated by Maslenitsky and Perlov (1960) that $99.5 \%$ of the contained tungsten could be recovered by the use of ball-mill autoclave. They have also suggested the use of calcium hydroxide to suppress bicarbonate formation. It was also reported that venting of the $\mathrm{CO}_{2}$ from autoclave, helped in decomposing biocarbonate.

2.2b Leaching of wolframite concentrate: Leaching of wolframite with sodium hydroxide solution at $110-130^{\circ} \mathrm{C}$ has been reported by Yih and Wang (1979). Over $98 \%$ of tungsten could be recovered from wolframite of particle size less than $44 \mu \mathrm{m}$ when $150 \%$ of the stoichiometric quantity of alkali was used. Qixiu Zhang et al (1988) have developed a process on pilot scale to recover tungsten as ammonium paratungstate from low grade refractory tungsten slimes containing wolframite and scheelite (18$28 \% \mathrm{WO}_{3}$ ) with high content of impurities such as tin, silicon, arsenic, molybdenum, calcium etc. The process consists of two-stage counter current leaching of the slime at a low pressure $\left(2 \mathrm{~kg} / \mathrm{cm}^{2}\right)$ in presence of $350 \mathrm{~g} / \mathrm{l}$ sodium hydroxide. After the sodium 
tungstate have been separated from the leach liquor by crystallization, fresh caustic soda is added to the alkali mother liquor for recycling.

Two typical processes based on caustic leaching have been developed recently in China, to treat low grade tungsten ore containing $20-30 \% \mathrm{WO}_{3}$. In the first process, developed by Zhou Ju-Qin and Xue Jian (1990) the concentrate is decomposed with high alkaii concentration. The leach solution is subjected to crystallization for the recovery of sodium tungstate while the mother liquor is transferred to the leaching section. The impure sodium tungstate crystals are dissolved in water and ammonium tungstate is recovered by ion exchange. In the second process, the leaching reaction is combined with mechanical activation of ore grinding, thus making the leaching process more effective than the traditional caustic digestion method. The new process developed by Honggui et al (1987) can treat tungsten concentrate of any type i.e. mixed scheelite and wolframite $\left(19-46 \% \mathrm{WO}_{3}\right)$ and scheelite of standard grade. Other advantages of the process claimed are: low energy consumption, high metal recovery and decrease in production cost by $15-20 \%$.

In India, the work on extraction of tungsten from wolframite concentrate has been carried out by Gokhale and Bhat (1966). They have studied the parameters such as: the amount of sodium carbonate, temperature and retention time on the extent of reaction with ore/concentrate containing $65 \% \mathrm{WO}_{3}$. Leaching of the roasted mass with water, precipitation of tungstic acid from the tungstate solution, purification of tungstic acid have also been conducted. An overall recovery of more than $98 \%$ tungsten have been reported by the authors. Gokhale and Gupta (1968) have further investigated the merits of the processes developed by BARC following the carbonate sintering and alkali leaching especially with respect to silica content of the tungstic oxide. It has been reported that the silica content in the alkali leach route was much less than the carbonate sintering process. Shamsuddin and Sohn (1981) have reviewed various alkali, acid leaching processes at atmospheric as well as at high pressure for extraction of tungsten from the wolframite and scheelite ores/concentrates. The studies carried out by Subramanian et al (1992) on extraction of tungsten from wolframite concentrate containing $24 \%$ $\mathrm{WO}_{3}$ from Degana, Rajathan, showed that more than $95 \%$ tungsten recovery is possible following the soda roasting and leaching route. The tungsten is recovered as oxide from the leach solution by precipitation, adsorption/desorption route.

2.2c Leaching of tungsten concentrate with ethylenediaminetetra-acetic acid $(E D T A)$ : The autoclave-soda process has the advantage that the low grade ores/concentrate containing as low as $1 \% \mathrm{WO}_{3}$ can be treated eliminating the ore dressing methods. However, the process operates at high pressure (12-26 bar) and high temperature $\left(190-225^{\circ} \mathrm{C}\right)$ and also calls for more reagent consumption. To overcome these, in the recent past use of chelating agent EDTA for selective extraction of tungsten from scheelite as well as wolframite concentrates has been proposed. Marshall (1983) has reported the extraction of tungsten from low grade scheelite ores $\left(0 \cdot 2-1 \cdot 32 \% \mathrm{WO}_{3}\right)$ and showed that aqueous EDTA solution could extract tungsten at atmospheric pressure. Apart from this, leach liquor produced could be directly used for tungsten extraction by solvent extraction. The process is less expensive and suitable for low grade $\left(0.5 \mathrm{WO}_{3}\right)$ residue dumps. Ke et al (1986) studied the dissolution rate of synthetic scheelite in aqueous EDTA and showed that rate was controlled by mass transfer. Konishi et al (1986) have reported the results of reaction kinetics of dissolution of scheelite in tetra sodium EDTA at atmospheric pressure. They found that the dissolution 
rate increased with decreasing initial particle size and with increasing temperature and concentration of EDTA.

\subsection{Recovery of tungsten from leach solution by solvent extraction}

The leach solution obtained after the treatment of ore/concentrate with acid/alkali contains impurities like silica, phosphorus, molybdenum, copper, tin etc. These impurities (Lassner 1982) are removed by $\mathrm{pH}$ adjustment and by the addition of various chemicals before subjecting to solvent extraction for the metal recovery. The solvent extraction technique has been used for recovering tungsten from leach solution obtained during processing of low and medium grade concentrate by pressure leaching methods. The major advantages of this technique are the possibility of using a wide variety of feed stock, continuous nature of process and less floor space requirement for the equipment.

Drobnick and Lewis (1962) patented a process to extract tungsten by using a secondary and tertiary amines, and reported the use of Alamine-336 and Aliquat-336, after purification of the solution produced in the leaching of the scheelite ore. The essence of the process is acidification of sodium tungstate solution to a $\mathrm{pH}$ of 1.5 to 3.5 leading to the formation of oxy-anionic complex of tungsten. This complex is extracted by the amine. The loading cycle is followed by stripping of the tungsten values from the organic phase using $5 \%$ ammonia solution to yield highly purified ammonium tungstate solution. Churchward and Bridges (1966) have reported a process using amines for recovering tungsten as APT from alkaline leach liquors. Over $90 \%$ of the tungsten in low grade scheelite containing 4.4-15\% $\mathrm{WO}_{3}$ and ferberite analysing $9 \cdot 7 \%$ $\mathrm{WO}_{3}$, is recovered as APT. The process consists of pressure leaching the concentrate with $\mathrm{Na}_{2} \mathrm{CO}_{3}$, solvent extraction of the acidified leach liquor with organic solvents of either a quaternary amine (Aliquat-336) or a primary amine (Primene JM-T), stripping the tungsten values from amine with $\mathrm{NH}_{4} \mathrm{Cl}$ or $\mathrm{NH}_{4} \mathrm{OH}$ and crystallization of ammonium paratungstate from the strip liquor.

A review on extraction of tungsten, molybdenum and vanadium from the different solutions has been carried out by Litz (1981) and he pointed out that these elements exhibit similar chemical properties. Therefore, they are recovered by relatively similar procedures following the sodium salt dissolution, solvent extraction and crystallization as ammonium sait of element. In the aqueous phase, these are present in the form of simple oxyanions above $\mathrm{pH} 7$ and complex oxyanionic polymers between $\mathrm{pH} 2$ to 7 and therefore these species could be extracted from the aqueous solution by amines and non-polar solvents. However, the $\mathrm{V}$ and Mo form the cations below pH 1 and could be extracted by organophosphoric acids or cation exchangers.

Hughes and Hanson (1983) investigated the transfer of the impurities viz. Na, Mo, P, $\mathrm{Si}$ during the solvent extraction of tungsten from the synthetic and actual leach solutions with Alamine 336 in kerosene. The studies revealed that the desired metal was contaminated with impurities where $\mathrm{Na}$ was mainly due to the physical entrainment of the aqueous molecule with the organic phase. It was possible to bring down the level of $\mathrm{Na}$ to $1 \mathrm{ppm}$ by simple water scrubbing. The other impurities form the hetropoly anions with amines and extracted during tungsten extraction. However, the concentration of these impurities decreased in the ammoniacal stripped solution which further reduced significantly in the final product, APT after crystallization. 
Table 1. Tungsten pre-concentrates showing the grade and amount received from $\mathrm{RSTDC}$.

\begin{tabular}{lccc}
\hline & & \multicolumn{2}{c}{ Grade $\left(\mathrm{WO}_{3} \%\right.$ ) analysed by } \\
\cline { 2 - 3 } Sample & Wt. (kg) & RSTDC & NML \\
\hline PC-1 & 260 & $11 \cdot 0$ & 14.5 \\
PC-2 & 225 & 30.0 & 28.48 \\
PC-3 & 200 & 40.0 & $39 \cdot 43$ \\
PC-4 & 200 & 60.0 & $53 \cdot 7$ \\
Jig conc. & 120 & $5 \cdot 0$ & 4.64 \\
Table conc. & 120 & $55 \cdot 0$ & 66.20 \\
\hline
\end{tabular}

Coca et al (1990) have summarized the processes of solvent extraction by different organic reagents. Primene JM-T, Aliquat-336, Alamine-336, Amberlite LA-2, Sulphoxides, di (2-ethylhexyl) phosphoric acid etc are the commercial extractant used for tungsten production. About $5-10 \%$ of the extractant in kerosene alongwith $5-10 \%$ of isododecanol or TBP as modifier has been used for extraction purpose. The modifier plays an important role as reported by Mac Innis and Kim (1983), in solubilizing the metal bearing organic species, aqueous-organic phase separation and elimination of third phase formation. Recently, Guedes De Carvalho and Sampaio (1991) have reported the extraction of tungsten from the synthetic solution using alkylamines in hydrochloric acid and sulphuric acid media. The relative efficiency of the different extractants and stripping agents has been compared.

The ammonium tungstate solution obtained from the solvent extraction is processed further by evaporation under atmospheric pressure (Mac Innis and Kim 1983). APT crystallizes out as a pentahydrate containing $89 \% \mathrm{WO}_{3}$ which is a precursor of pure $\mathrm{WO}_{3}$.

\section{R and D work at NML}

The experimental work on beneficiation, purification and extraction of tungsten from different pre-concentrate samples were undertaken on the request of the Defence Metallurgical Research Laboratory (DMRL), Hyderabad. A total of six such samples analysing tungsten between $4.46 \%$ to $66.2 \% \mathrm{WO}_{3}$ (table 1) were received from the Rajasthan State Tungsten Development Corporation (RSTDC), who are producing concentrate containing $+65 \% \mathrm{WO}_{3}$ from the only working mine in the country today at Degana, Rajasthan. The following were the main objectives:

- to improve the grade of the pre-concentrates to desired specification i.e. $+65 \%$ $\mathrm{WO}_{3}$, by physical method*

- to purify the table concentrate from deleterious impurities like silica and sulphur by chemical treatment

- to extract tungsten values from the low grade jig concentrate.

The pre-concentrate samples viz PC-1 to PC-4 were subjected to physical method of beneficiation to improve the grade while a small quantity of the table and jig concentrates

* will not be discussed in this report 
were available for processing by chemical route. During physical beneficiation of pre-concentrates by flotation, two fractions namely 'float' rich in sulphur and 'nonfloat' rich in silica were generated and termed as 'middlings'. Since these contain high value of tungsten $(\sim 18-20 \%)$, they were given chemical treatment to recover the metal. But prior to chemical treatment, the samples were examined mineralogically to know the distribution of tungsten and other associated gangue present in the table concentrate, middlings and jig concentrate samples.

\subsection{Mineralogical studies}

The studies were carried out on samples prepared from table concentrate, middlings and jig concentrate. According to the mineralogical analysis wolframite is found to be the main tungsten bearing mineral in all the samples which are also associated with metallic (iron sulphide, arsenopyrite, chalcopyrite, and magnetite) and non-metallic (topaz, quartz, feldspar, mica and fluorite) minerals.

Since the jig concentrate was the major sample, close examination was carried out with a view to know the nature of distribution and interlocking of tungsten minerals. It was found that about $15 \%$ of wolframite was locked in coarse size upto 208 micron and could be recovered by physical beneficiation, whereas $65 \%$ was present in fine size range i.e. upto 74 micron. Recovery of the latter would be very difficult by physical method because of more slime production. Remaining $20 \%$ of the wolframite was found interlocked in the very fine to ultrafine size (less than 44 micron) fraction which cannot be recovered. In order to recover tungsten values from such a concentrate, chemical processing appears to be the only answer.

\subsection{Processing of the table concentrate}

The table concentrate apart from tungsten, contained $2 \cdot 22 \%$ silica and $1 \cdot 81 \%$ sulphur as the major impurities, and did not meet the desired specification for tungsten production. The chemical analysis of the concentrate is given in table 2 .

3.2a Removal of silica from table concentrate: The concentrate was cured with hydrofluoric acid of desired concentration for a predetermined period. After filtration the residue was thoroughly washed to make it free from soluble salts and acid before drying at $110^{\circ} \mathrm{C}$. The filtrate and residue were analysed for silica and tungsten content. Parameters such as amount and concentration of acid, particle size and curing time were studied to optimize the conditions for silica removal from the concentrate.

Table 2. Chemical analysis of table concentrate.

\begin{tabular}{lccl}
\hline Constituent & Wt. \% & Constituent & Wt $\%$ \\
\hdashline $\mathrm{WO}_{3}$ & 66.2 & Mo & 0.018 \\
$\mathrm{SiO}_{2}$ & 2.22 & $\mathrm{Ca}$ & trace \\
$\mathrm{Cu}$ & 0.021 & $\mathrm{~S}$ & 1.81 \\
$\mathrm{Fe}$ & 11.28 & $\mathrm{P}$ & trace \\
$\mathrm{Mn}$ & 4.46 & F & 9.6 \\
\hline
\end{tabular}


Table 3. Results of desilication test with HF,

\begin{tabular}{|c|c|c|c|c|c|c|}
\hline \multirow{2}{*}{$\begin{array}{l}\text { Sl. } \\
\text { No. }\end{array}$} & \multirow{2}{*}{$\begin{array}{l}\text { Amount of } \\
\text { concentrate } \\
\text { (g) }\end{array}$} & \multirow{2}{*}{$\begin{array}{l}\text { Volume of } \\
\text { hydrofluoric } \\
\text { acid } \\
\text { (ml) }\end{array}$} & \multirow{2}{*}{$\begin{array}{l}\text { Wt. of } \\
\text { enriched } \\
\text { product } \\
\text { (g) }\end{array}$} & \multicolumn{2}{|c|}{$\begin{array}{c}\text { Chemical analysis of enriched } \\
\text { product }\end{array}$} & \multirow{2}{*}{$\begin{array}{c}\text { Loss of } \mathrm{WO}_{3} \\
(\%)\end{array}$} \\
\hline & & & & $\% \mathrm{WO}_{3}$ & $\% \mathrm{SiO}_{2}$ & \\
\hline 1. & 100 & 40 & 93.5 & 67.02 & 0.60 & $3 \cdot 5$ \\
\hline 2. & 500 & 200 & $460 \cdot 0$ & 66.90 & 0.63 & $3 \cdot 5$ \\
\hline 3. & 1000 & 400 & 9200 & $66 \cdot 50$ & 0.60 & $3 \cdot 6$ \\
\hline 4. & 3000 & 1200 & 27500 & $66 \cdot 20$ & 0.72 & 3.7 \\
\hline
\end{tabular}

Particle size of concentrate: $-152 \mu \mathrm{m}$.

Period of curing: $24 \mathrm{~h}$

Table 4. Removal of sulphur from desilicated tungsten concentrate.

\begin{tabular}{lcc}
\hline & $\begin{array}{c}1 \mathrm{~kg} \mathrm{scale} \\
\text { trial }\end{array}$ & $\begin{array}{c}3 \mathrm{~kg} \mathrm{scale} \\
\text { trial }\end{array}$ \\
\hline $\begin{array}{l}\text { Weight of concentrate } \\
\text { Weight of desilicated product }\end{array}$ & $\begin{array}{c}1000 \mathrm{~g} \\
920 \mathrm{~g}\end{array}$ & $3000 \mathrm{~g}$ \\
Calcination temperature & $650^{\circ} \mathrm{C}$ & $650^{\circ} \mathrm{C}$ \\
Calcination time & $2 \mathrm{~h}$ & $2 \mathrm{~h}$ \\
Weight of final product & $905 \mathrm{~g}$ & $2705 \mathrm{~g}$ \\
Sulphur in final product & $0-17 \%$ & $0.18 \%$ \\
\hline
\end{tabular}

During curing tests different amount (volume) of hydrofluoric acid (48\% strength) was added for selective removal of silica from the concentrate. It was found that the silica content decreases steadily from 2.22 to $1 \cdot 10 \%$ on increasing the amount of hydrofluoric acid from $3 \mathrm{ml}$ to $20 \mathrm{ml}$. Thereafter, there is no appreciable improvement in silica removal even on curing with $40 \mathrm{ml}$ hydrofluoric acid. With optimum amount of hydrofluoric acid, a series of experiments were carried out by taking different particle size of the concentrate to examine its effect on removal of silica. It was observed that concentrate having - 152 micron size was most effective for maximum desilication. However, there was loss of $\mathrm{WO}_{3}$ when finer fractions of concentrate was used. After optimizing the amount of hydrofluoric acid the concentrate was treated for different period. The silica content decreased from $2 \cdot 22$ to $0.66 \%$ as duration of curing was increased from 6 to $24 \mathrm{~h}$ at ambient temperature.

A number of curing tests were next carried out with different strength of hydrofluoric acid using essentially optimum size fraction of the concentrate and curing time as already established for desilication. It was observed that dissolution of silica increased with increase of hydrofluoric acid strength and the silica content in the product decreased from 2.22 to $0.66 \%$ on increasing the strength of acid from 16 to $48 \%$ with marginal loss of tungsten value. It was also observed that there was no improvement in silica dissolution even on increasing the acid strength beyond $48 \%$. Based on the optimum conditions arrived in bench scale studies curing tests upto $3 \mathrm{~kg}$ scale (batch) were conducted for silica removal. These data are given in table 3.

3.2b Removal of sulphur from desilicated product: The desilicated product was subjected to roasting in presence of air for removal of sulphur and the results are 
Table 5. Results of oxidation roasting of S-rich middling.

\begin{tabular}{ccc}
\hline Time (min) & ${ }^{\circ} \mathrm{WO}_{3}$ in product & \% S in the product \\
0 & 15.73 & 27.0 \\
30 & 17.70 & 18.79 \\
60 & 19.81 & 11.60 \\
90 & 20.46 & 5.77 \\
120 & 20.35 & 1.96 \\
150 & 20.66 & 0.12 \\
\hline
\end{tabular}

Wt. of sample: $350 \mathrm{~g}$ : time: $2 \cdot 5 \mathrm{~h}$ : temperature: $700 \mathrm{C}$.

Table 6. Leaching of the roasted middlıng.

\begin{tabular}{lc}
\hline Amount of roasted product & $200 \mathrm{~g}$ \\
$\mathrm{WO}_{3}$ in the roasted product & $20.66^{\circ} \%$ \\
Solid:liquid ratio & $1: 3$ \\
Temperature & $150 \mathrm{C}$ \\
Pressure & $15 \mathrm{bar}$ \\
Time & $2 \mathrm{~h}$ \\
o extraction of $\mathrm{WO}_{3}$ in leach solution & $93 \%$
\end{tabular}

presented in table 4. It was found that a temperature of $650 \mathrm{C}$ and $120 \mathrm{~min}$ were sufficient to bring down the sulphur within the limit. It may be seen from table 4 that the sulphur content decreased from 1.8 to $0.17 \%$ in the final product.

From bench scale tests it was observed that over $75 \%$ silica could be removed from table concentrate on curing with concentrated hydrofluoric acid $(48 \%)$ and thus lowering the level of silica content from 2.22 to $0.60 \%$ with little loss of tungsten. The desulphurization tests showed that $90 \%$ of sulphur was removed by roasting the desilicated concentrate for $120 \mathrm{~min}$ at $650 \mathrm{C}$, lowering down the level of sulphur content from 1.8 to $0.17 \%$. Hence it may be concluded that the combined process of desilication and subsequent roasting of the concentrate is an affective technique for purification of tungsten concentrate with a marginal loss of tungsten. The product thus obtained meets the desired specification laid down by DMRL.

\subsection{Treatment of middlings}

Middlings are intermediate product obtained during flotation of the pre-concentrates. The 'float' portion was rich in sulphur whereas 'non-float' was rich in silica. The tungsten and sulphur content in sulphur rich middling vary between $18-20 \% \mathrm{WO}_{3}$ and $27-30 \% \mathrm{~S}$ respectively, whereas the non-float portion contained $10-18 \% \mathrm{WO}_{3}$ and rest was silica. Middlings were not amenable to physical beneficiation because the tungsten minerals were interlocked and at times rimmed with sulphide minerals like pyrite, chalcopyrite etc.

3.3a Processing of sulphur and silic a rich middlings: In order to recover the tungsten from the middling rich in sulphur, it was given oxidative roasting to alter/destroy the 
sulphur rim, thus making it amenable to leaching. The roasting was carried out in air for different lengths of time to optimize the conditions. The results of roasting are given in table 5 . It may be seen from table 5 that after roasting the sample for $120 \mathrm{~min}$ at $700^{\circ} \mathrm{C}$, almost all the sulphur was removed. The roasted product was then leached under pressure with sodium carbonate. The amount of soda, effect of temperature and pressure were optimized for maximum recovery of tungsten. The conditions of leaching are given in table 6 . The sodium tungstate solution obtained after alkali pressure leaching was purified for silica by adjusting pH to 8 and the precipitated silica was removed by filtration. The other impurities were removed by addition of sodium sulphide between the $\mathrm{pH} 2$ to 3. Tungsten was recovered as tungstic oxide by precipitation and calcination. It was possible to recover over $90 \%$ tungsten in the form of tungstic oxide from middling rich in sulphur.

The silica rich middling was directly leached with sodium carbonate solution at the same temperature and pressure as used in the case of sulphur rich middling. The solution obtained during leaching was purified for silica and subsequently processed for tungsten recovery. The overall recovery of tungsten as $\mathrm{WO}_{3}$ was $90 \%$.

\subsection{Processing of jig concentrate}

The low grade jig concentrate produced and stock-piled at Degana, Rajasthan by the RSTDC, contained $4.6 \% \mathrm{WO}_{3}$. Since this concentrate was the major product, it was considered worthwhile to develop a viable process to extract the metal from this concentrate. The process route developed consists of alkali pressure leaching followed by solvent extraction, precipitation and crystallization of tungsten as ammonium paratungstate.

3.4a Leaching studies: The jig concentrate sample as received was 2000 micron in size. This was ground to -100 micron size before leaching. Experiments were performed in a two litre autoclave by taking $200 \mathrm{~g}$ of sample each time. The parameters such as effect of alkali concentration, pressure, temperature and time of leaching were studied.

Table 7. Effect of leaching time on recovery of $\mathrm{WO}_{3}$ from jig concentrate.

\begin{tabular}{lcc}
\hline Sl No. & $\begin{array}{c}\text { Time } \\
(\mathrm{min})\end{array}$ & $\begin{array}{c}\text { WO }_{3} \text { extraction } \\
(\%)\end{array}$ \\
\hline 1. & 30 & 45.8 \\
2. & 60 & 58.2 \\
3. & 90 & 80.6 \\
4. & 120 & 95.5 \\
5. & 150 & 95.6 \\
6. & 180 & 95.3 \\
7. & 240 & 95.0 \\
\hline
\end{tabular}

Temperature: $150 \mathrm{C}$; pressure: 15 bar: solid: liquid ratio: $1: 3$ 
Table 8. Effect of temperature and pressure.

\begin{tabular}{lccc}
\hline $\begin{array}{l}\text { Si. } \\
\text { No. }\end{array}$ & $\begin{array}{c}\text { Temp. } \\
(\mathrm{C})\end{array}$ & $\begin{array}{c}\text { Pressure } \\
\text { (bar) }\end{array}$ & $\begin{array}{c}\mathrm{WO}_{3} \text { extraction } \\
(\%)\end{array}$ \\
\hline 1. & 100 & 10.0 & $73 \cdot 8$ \\
2. & 150 & 15.0 & $95 \cdot 5$ \\
3. & 170 & $17 \cdot 0$ & 96.5 \\
4. & 200 & 20.0 & 97.0 \\
5. & 225 & 22.0 & 96.8 \\
\hline
\end{tabular}

Solid:liquid ratio: $1: 3$; amount of soda: $15 \%$; time: $120 \mathrm{~min}$.

Table 9. Effect of alkali (soda) concentration. Pressure, temperature and time were constant.

\begin{tabular}{lcc}
\hline $\begin{array}{l}\text { Si. } \\
\text { No. }\end{array}$ & $\begin{array}{c}\text { Alkali concentration } \\
(\mathrm{g} / \mathrm{l})\end{array}$ & $\begin{array}{c}\text { WO }_{3} \text { extraction } \\
(\%)\end{array}$ \\
\hline 1. & 25 & 28.5 \\
2. & 50 & 49.6 \\
3. & 100 & 64.9 \\
4. & 150 & 95.5 \\
5. & 200 & 95.0 \\
\hline
\end{tabular}

Table 10. Results of lock cycle leaching experiments. Pressure, temperature and time were constant.

\begin{tabular}{lccc}
$\begin{array}{l}\text { Cycle } \\
\text { No. }\end{array}$ & $\begin{array}{c}\text { Concentration of } \\
\mathrm{WO}_{\mathbf{3}}, \mathrm{g} / \mathrm{l}\end{array}$ & $\begin{array}{c}\mathrm{WO}_{\mathbf{3}} \text { extraction } \\
(\%)\end{array}$ & $\begin{array}{c}\text { Consumption of } \\
\text { soda/g WO }\end{array}$ \\
\hline 1. & $8 \cdot 10$ & $95 \cdot 24$ & 3.87 \\
2. & 11.60 & 90.20 & 3.53 \\
3. & 12.90 & $94 \cdot 10$ & 2.65 \\
4. & 13.46 & 89.00 & 2.93 \\
5. & 13.68 & 94.80 & 3.34 \\
6. & 13.79 & 96.10 & 3.05 \\
7. & 13.82 & 92.40 & 3.25 \\
8. & 13.83 & 94.17 & 3.85 \\
9. & 13.83 & 93.70 & 3.28 \\
\hline
\end{tabular}

Results of leaching time on the recovery of $\mathrm{WO}_{3}$ in solution is given in table 7 , whereas table 8 gives the effect of temperature and pressure on the same. It can be seen from table 7 that 120 min leaching time was sufficient for the maximum extraction of $\mathrm{WO}_{3}$ in leach solution. After fixing the time, pressure and temperature were varied and it was found that over $95 \%$ of $\mathrm{WO}_{3}$ could be extracted at a temperature of $150^{\circ} \mathrm{C}$ and pressure of 15 bar. However, further increase in temperature and pressure did not result in any appreciable increase in the recovery.

Effect of alkali concentration on the recovery of tungsten is given in table 9. From the table it can be seen that the optimum concentration of soda was $150 \mathrm{~g} / \mathrm{l}$. In all these 
Table 11. Leach liquor feed before and after purification.

\begin{tabular}{|c|c|c|c|c|}
\hline \multirow[b]{3}{*}{ Component } & \multirow{2}{*}{\multicolumn{2}{|c|}{$\frac{\begin{array}{c}\text { Leach liquor } \\
\text { without purification }\end{array}}{(\mathrm{g} / \mathrm{l})}$}} & \multirow{2}{*}{\multicolumn{2}{|c|}{$\begin{array}{c}\begin{array}{c}\text { Leach liquor } \\
\text { after purification }\end{array} \\
(\mathrm{g} / \mathrm{l})\end{array}$}} \\
\hline & & & & \\
\hline & (A) & (B) & (A) & (B) \\
\hline \multirow{4}{*}{$\begin{array}{l}\mathrm{WO}_{3} \\
\mathrm{Mo} \\
\mathrm{SiO}_{2} \\
\mathrm{P}\end{array}$} & $15 \cdot 60$ & $10 \cdot 20$ & $15 \cdot 1$ & $9 \cdot 81$ \\
\hline & 0.014 & 0.018 & 0.006 & 0.005 \\
\hline & $0 \cdot 38$ & 0.210 & 0.09 & 0.008 \\
\hline & 0.02 & 0.022 & 0.007 & 0.004 \\
\hline
\end{tabular}

experiments the concentration of $\mathrm{WO}_{3}$ obtained in the leach liquor was $8-9 \mathrm{~g} / \mathrm{l}$. To increase the concentration of $\mathrm{WO}_{3}$ in solution for its subsequent processing by solvent extraction, further experiments were carried out on lock cycle mode by recycling $40 \%$ of the leach liquor obtained, in leaching circuit. The results of these recycle leaching are given in table 10 . It can be seen from table 10 that after 7 cycles, steady state condition was reached and $\mathrm{WO}_{3}$ concentration in leach liquor increased from $8.1 \mathrm{~g} / 1$ to $13.82 \mathrm{~g} / \mathrm{l}$ with an average soda consumption of $3.3 \mathrm{~g}$ per $\mathrm{g}$ of $\mathrm{WO}_{3}$ leached out.

3.4b Purification of leach solution: Purification of leach solution before subjecting to solvent extraction is an important step because of two reasons namely possibility of achieving better loading capacity of the solvent and production of ammonium paratungstate with total impurities less than $200 \mathrm{ppm}$. The leach solution obtained from different batches were mixed to get a homogeneous composition and named as solution A and $B$. The analysis of these solutions for some of the impurities are given in table 11 . The impurity level in the leach solutions was high and therefore, their removal was carried out. The $\mathrm{pH}$ of the solution was decreased to a value of 7.5 by neutralization with sulphuric acid thereby precipitating silica. The solution was filtered and the filtrate was further neutralized to 3-4 $\mathrm{pH}$. Sodium sulphide was then added to precipitate molybdenum, phosphorus and some other impurities. The solution was clarified and $\mathrm{pH}$ adjusted for solvent extraction studies. The results given in table 11 indicate some loss of tungsten due to co-precipitation/adsorption of the metal with the impurities. The level of molybdenum, phosphorus and silica was reduced to 5-6;8-9 and 4-7 ppm respectively after purification.

3.4c Extraction of tungsten from leach solution: Preliminary experiments were carried out with the synthetic solution of similar composition as produced in the leaching. Alamine-336, supplied by $\mathrm{M} / \mathrm{s}$. Henkel Corporation, USA along with isodecanol diluted with kerosene was used as the extractant (organic phase). The aqueous and the organic phases in definite proportion were mixed together in a stirred vessel of perspex for the desired time and separated in a funnel. The loaded organic after washing was stripped with ammonium hydroxide solution and tungsten was obtained as APT. From this solution, APT was crystallized by evaporation.

Before actual experiment with leach solution the extraction isotherm was obtained by repeated contact of the organic with the feed solution of the known pH keeping organic to aqueous ratio of $1: 1$. The results depicted in figure 1 show that the extraction of tungsten increases with the rise of equilibrium aqueous $\mathrm{pH}$ from $1 \cdot 71$ to $2 \cdot 10$ and then 


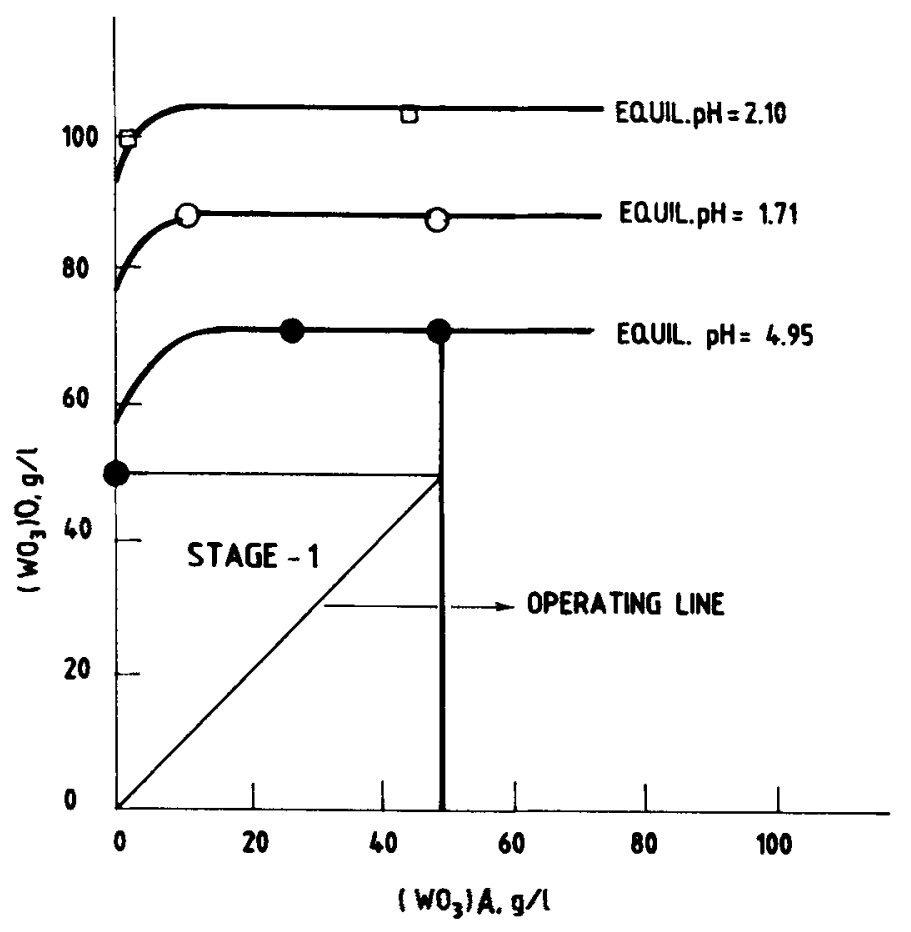

Figure 1. Extraction isotherm of tungsten at different pH. Solvent: 10\% Alamine 336 and $10 \%$ isodecanol in kerosene. Aq. feed $=50 \mathrm{~g} \mathrm{WO}_{3} / 1$ and $\mathrm{A}: \mathrm{Q}=1: 1$.

decreases with further increase in $\mathrm{pH}$ to 4.95 . From the isotherm and the operating line drawn at $\mathrm{A} / \mathrm{O}$ of 1 it is also clear that single stage is sufficient to extract $50 \mathrm{~g} \mathrm{WO}_{3} / \mathrm{from}$ aqueous solution of $\mathrm{pH} 1.71-4.95$ by using $10 \%$ Alamine and $10 \%$ isodecanol in kerosene.

3.4d Effect of $p H$ on extraction of tungsten: The $\mathrm{pH}$ of the solution plays an important role in the extraction of tungsten as the ionic species of the tungsten changes with the variation of $\mathrm{pH}$. Initially, the effect of $\mathrm{pH}$ was studied with synthetic solution without sulphatizing the solvent. It was found that the percentage extraction of metal decreases sharply with increase of aqueous feed $\mathrm{pH}$ beyond 6.5. Extraction of tungsten was also investigated by sulphatizing the solvent at different $\mathrm{pH}$. The results indicate that extraction of tungsten is even possible up to feed $\mathrm{pH}$ of $10 \cdot 50$. Thus, the sulphatized form of the solvent was found to be more suitable in respect of availability of wider feed $\mathrm{pH}$ range for tungsten extraction than non-sulphatized solvent.

3.4e Extraction of tungsten at different $A: O$ ratio: Extraction of tungsten at different $\mathrm{A} / \mathrm{O}$ with synthetic $\left(10 \mathrm{~g} \mathrm{WO}_{3} / \mathrm{pH}=1.85\right)$ and actual leach $\left(\mathrm{WO}_{3}=9.81 \mathrm{~g} \mathrm{WO}_{3} / \mathrm{l}\right.$, $\mathrm{pH}=1.9$ ) liquors was also carried out and results are presented in tables 12 and 13 . It follows from these results that the maximum loading of the tungsten to the tune of $67.5 \mathrm{~g} \mathrm{WO}_{3} / 1$ in the organic phase from the leach liquor takes place till $\mathrm{A} / \mathrm{O}$ ratio of $7: 1$ and then the tungsten-organic complex starts precipitating near the interphase. The loading capacity of the solvent with the synthetic solution on the other hand is much higher i.e. $102 \cdot 1 \mathrm{~g} \mathrm{WO}_{3} / 1$ obtained at $\mathrm{A} / \mathrm{O}$ ratio of $15: 1$. The lower value of the loading 
Table 12. Loading capacity of the solvent with synthetic solution of tungsten.

\begin{tabular}{lccc}
\hline Sl. No. & A:O ratio & Equil. (pH) & $\begin{array}{c}\text { Loaded solvent } \\
\text { (WO }), g / 1\end{array}$ \\
\hline 1. & $1: 1$ & $1 \cdot 12$ & 9.98 \\
2. & $2: 1$ & 1.25 & 19.96 \\
3. & $3: 1$ & 1.30 & 29.94 \\
4. & $4: 1$ & 1.30 & 39.90 \\
5. & $5: 1$ & 1.37 & $49 \cdot 87$ \\
6. & $10: 1$ & 1.55 & $99 \cdot 75$ \\
7. & $15: 1$ & 1.78 & 102.11 \\
\hline
\end{tabular}

Solvent: $10 \%$ Alamine-336 and $10 \%$ isodecanol in kerosene after sulphatization; aq. feed: $10 \mathrm{~g} \quad \mathrm{WO}_{3} /, \mathrm{pH}=1.85$, $t=600 \mathrm{~S}$.

Table 13. Loading capacity of the solvent with leach liquor feed.

\begin{tabular}{lccc}
\hline Sl. No. & A:O ratio & Equil. $(\mathrm{pH})$ & $\begin{array}{c}\text { Loaded solvent } \\
\left(\mathrm{WO}_{3}\right), \mathrm{g} / 1\end{array}$ \\
\hline 1. & $1: 1$ & $1 \cdot 40$ & $9 \cdot 76$ \\
2. & $2: 1$ & $1 \cdot 70$ & $19 \cdot 52$ \\
3. & $3: 1$ & $1 \cdot 70$ & $29 \cdot 19$ \\
4. & $4: 1$ & $1 \cdot 70$ & 38.58 \\
5. & $5: 1$ & $1 \cdot 70$ & $48 \cdot 23$ \\
6. & $6: 1$ & $1 \cdot 75$ & $57 \cdot 79$ \\
7. & $7: 1^{*}$ & $1 \cdot 80$ & 67.52 \\
\hline
\end{tabular}

Solvent: $10 \%$ Alamine-336 and $10 \%$ isodecanol in kerosene after sulphatization; aq. feed: $9.81 \mathrm{~g} \mathrm{WO}_{3} / \mathrm{l}, \mathrm{pH}=1.90$, $t=600 \mathrm{~S}$.

* At $\mathrm{A}: \mathrm{O}=7: 1$, the tungsten from the loaded solvent starts precipitating in the aqueous phase.

capacity $\left(67.5 \mathrm{~g} \mathrm{WO}_{3} / 1\right)$ of the solvent with actual leach solution as compared to the loading of $102 \cdot 1 \mathrm{~g} \mathrm{WO}_{3} / 1$ from the synthetic solution may be attributed to the presence of various impurities in the leach solution resulting in the precipitation of tungsten organic complex near the aqueous phase.

$3.4 \mathrm{f}$ Stripping of tungsten from the loaded organic: The stripping of the loaded organic was carried out with ammonium hydroxide solution. To study the stripping of tungsten, $10 \%$ Alamine-336 was contacted with aqueous solution of $100 \mathrm{~g} \mathrm{WO}_{3} / 1$ and the extracted tungsten value $\left(99.73 \mathrm{~g} \mathrm{WO}_{3} / 1\right)$ after scrubbing was stripped with $3 \mathrm{~N} . \mathrm{NH}_{4} \mathrm{OH}$ solution at $\mathrm{A}: \mathrm{O}$ of $1: 1$. The concentration of tungsten in the aqueous and organic phases in all the contacts was computed and stripping isotherm plotted. Data given in figure 2 indicate that one stage is sufficient to strip $99.7 \%$ of the loaded tungsten from the organic at $\mathrm{A} / \mathrm{O}$ of 1 . The experiments with actual leach liquor also reveals the similar stripping efficiency as compared to synthetic solution. 


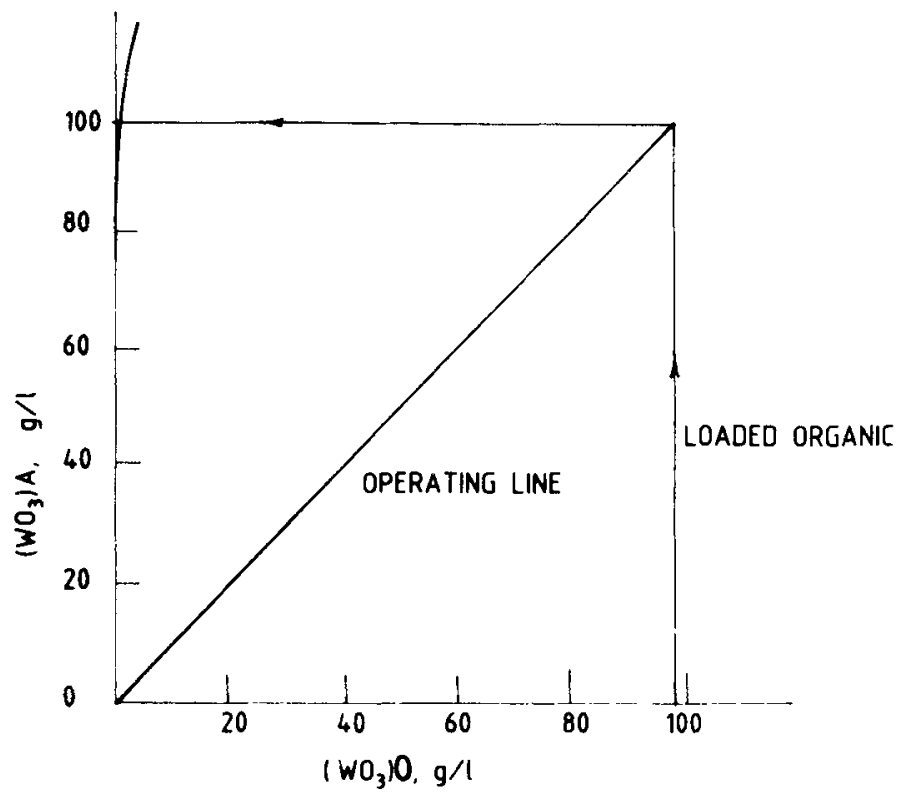

Figure 2. Tungsten stripping isotherm. Solvent $=10 \%$ Alamine 336 and $10 \%$ isodecanol in kerosene. Loaded organic $=99 \cdot 73 \mathrm{~g} \mathrm{WO}_{3}$ l; stripping solution $=3 \mathrm{~N} \mathrm{NH} \mathrm{NH}_{4} \mathrm{OH}: \mathrm{A}: \mathrm{O}=1: 1$.

STRIPPING REAGENT

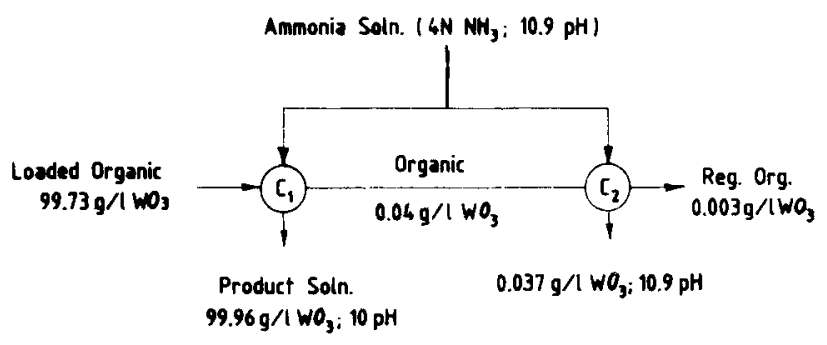

STRIPPWG REAGENT STRIPPING REAGENT

- Ammoniun tungstate Soln. $\quad\left(4 \mathrm{~N} \mathrm{NH}_{3}: 10.9 \mathrm{pH}\right)$

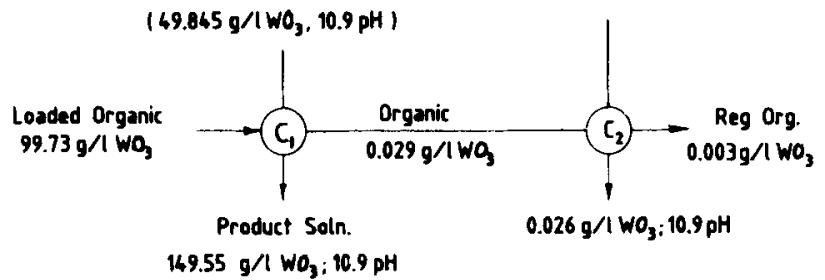

ORG. $/ \mathrm{AQ} .=1150 \mathrm{ml}$ EACH $) \mathrm{C}_{1-2}=$ CONTACT No. 182

ORGANIC $=10 \%$ ALAMINE $336 \& 10 \%$ ISODECANOL IN KEROSENE

- AMMONIICA SOLUTION OF $49.845 \mathrm{~g} / 1 \mathrm{WO}_{3}$ WAS MADE USING

HALF VOLUME OF $99.69 \mathrm{~g} / \mathrm{l}$. W0 $3(10 \mathrm{pH})$ AND DILUTED TO GET

1:1 PHASE RATIO

Figure 3. Stripping of tungsten loaded from the synthetic aqueous solution. 


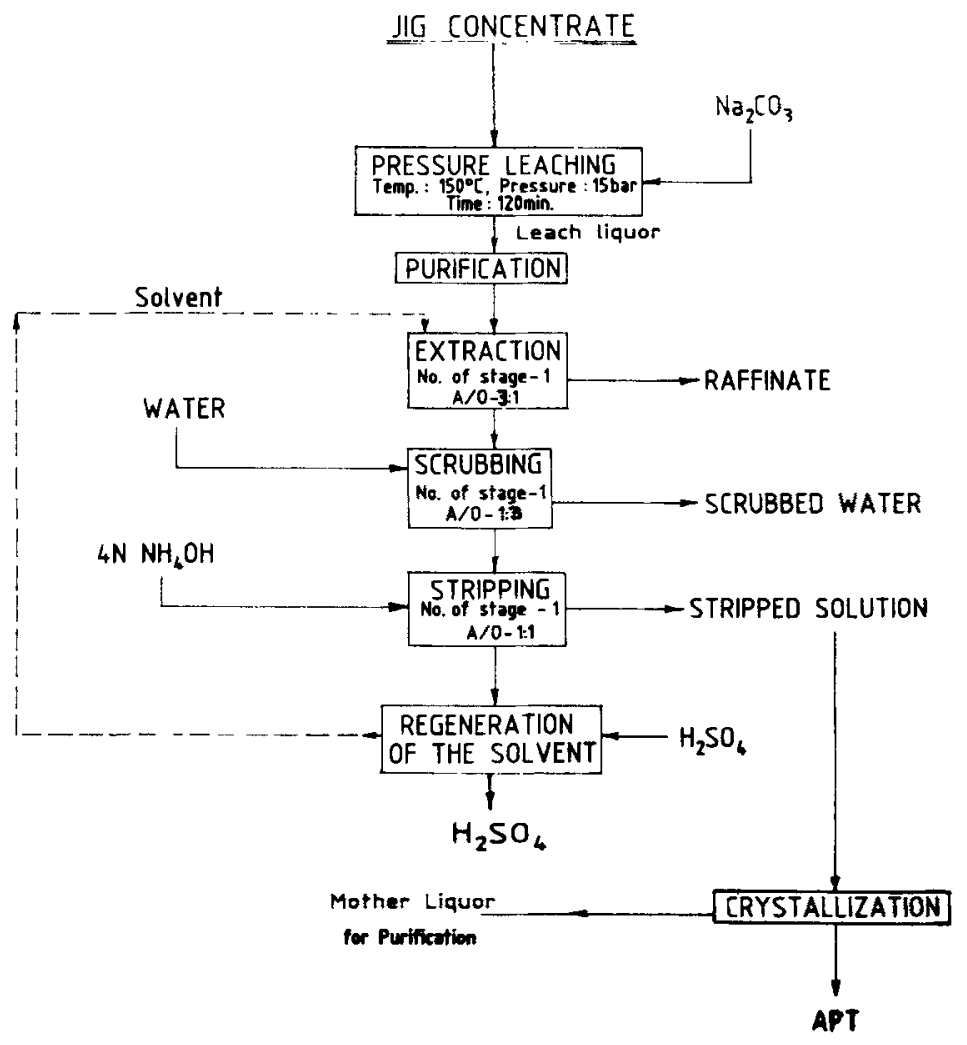

Figure 4. General scheme for extraction of tungsten from jig concentrate.

Effect of $\mathrm{NH}_{4} \mathrm{OH}$ concentration ( 1 to $4 \mathrm{~N}-\mathrm{NH}_{4} \mathrm{OH}$ ) on the stripping of loaded organic was performed at $\mathrm{A} / \mathrm{O}$ of 1 . The results revealed that even $2 \mathrm{~N} \cdot \mathrm{NH}_{4} \mathrm{OH}$ solution is sufficient to effect almost quantitative stripping of the metal.

In order to see the stripping efficiency with tungsten solution turning out from the crystallizer (APT), it was considered to use partially the stripped solution obtained from $\mathrm{C}_{1}$ (figure 3 ). In $50 \%$ amount of stripped solution, concentrated ammonia was added to adjust the $\mathrm{pH}$ to 10.9 and this solution having $49.845 \mathrm{~g} \mathrm{WO}_{3} / 1$ was used to strip the loaded organic containing $99.73 \mathrm{~g} \mathrm{WO}_{3} / \mathrm{l}$. It is apparent from the figure that the stripping efficiency of the loaded organic remains the same and the enrichment of the aqueous stripped solution is suitable for metal recovery by crystallization. The crystallization was carried out with synthetic as well as actual leach liquor after stripping. The solution containing about $100 \mathrm{~g} / 1 \mathrm{WO}_{3}$ was evaporated in a thermostatic water bath. About $60 \%$ of tungsten was crystallized as APT. The mother liquor containing impurities like $\mathrm{Mo}, \mathrm{Si}, \mathrm{P}, \mathrm{Ca}, \mathrm{Mg}$ etc. was recycled and purified for metal recovery.

From the above studies it emerges that the Alamine-336 and $10 \%$ isodecanol in kerosene is effective for the extraction of tungsten from the leach liquor of jig concentrate and stripping of the loaded metal with ammonium hydroxide. Finally, tungsten can be recovered from the stripped solution as ammonium paratungstate by crystallization. The kinetics of extraction and stripping is so favourable that the solvent 
can be efficiently utilized for recovery of metal in the mixer-setter unit. A general scheme for the extraction of tungsten from the leach solution is presented in figure 4 .

\section{Gap areas}

The experiments conducted so far to recover tungsten from low grade jig concentrate containing $4 \cdot 6 \% \mathrm{WO}_{3}$ were on batch scale of $200 \mathrm{~g}$. The process parameters have been optimized. However, to establish the techno-economic feasibility of the process a comprehensive programme consisting of physical beneficiation of the ore to produce concentrate with $5-10 \% \mathrm{WO}_{3}$ followed by pressure leaching, purification, solvent extraction and crystallization to produce APT of standard grade is necessary. The following experiments on hydrometallurgical processing of the concentrate needs to be conducted:

(a) Lock cycle leaching experiments on $5 \mathrm{~kg}$ scale to establish the number of cycles for a steady state composition.

(b) Effect of impurities build-up during recycling of leach liquor and its removal in subsequent stages.

(c) Continuous solvent extraction trial run in mixer-settler for at least $100 \mathrm{~h}$, to know the extraction and stripping efficiency in the closed circuit.

(d) Effect of impurities build-up during continuous solvent extraction run to determine the cut-off impurity level for down-stream processing.

(e) Crystallization studies to produce APT on a continuous basis and recycling of mother liquor and other solutions.

(f) Use of other lixiviant systems like sodium hydroxide, mixture of soda and sodium hydroxide, EDTA etc.

\section{Conclusions}

- The survey of the hydrometallurgical processes for recovering tungsten from low grade concentrate consists of mainly, pre-treatment, alkali pressure leaching with soda followed by solvent extraction with Alamine/Aliquat-336 and crystallization to produce APT. Concentrates analysing as low as $1 \% \mathrm{WO}_{3}$ have been treated by the above route.

- The R and D work done at NML on purification and recovery of tungsten from different off-grade products such as table concentrate, middlings rich in sulphur and silica, and jig concentrate showed that it was possible to remove impurities like silica and sulphur to an extent of 75 and $90 \%$ respectively from the table concentrate and recover tungsten as APT from jig concentrate with an yield of $92 \%$. The process was developed on the lab-scale ( $200 \mathrm{~g}$ of concentrate) and upscaling would be needed to validate the bench scale data.

- The process flow-sheet developed can treat any type of concentrate produced from low grade Indian ores.

\section{Acknowledgement}

Thanks are due to Dr B D Pandey, Dr V Kumar, Shri D Jha and other scientists of the NFP Division for their support in collecting information. The financial support for 
carrying out the work from the Defence Research and Development Organization, Hyderabad, is also acknowledged.

\section{References}

Bhat T R and Gokhale Y W 1966 BARC Report No. A.E.E.T/251

Bhosale S N, Mookherjee S and Pardeshi R M 1990 High Temp. Mater. \& Processes 9147

Churchward P E and Bridges D W 1966 US Bureau of Mines, Report of Investigation, p. 6845

Coca J, Diez F V and Moris M A 1990 Hydrometallurgy 25125

Drobnik J L and Lewis C J 1962 US Patent 3, 052, 516

Gokhale Y W and Gupta S S 1968 Report No. BARC, p. 380

Guedes De Carvalho R A and Sampaio M N M 1991 Hydrometalluray 26137

Hamilton E M 1918 US Patent 1, 261, 383

Honggui Li, Maosheng Liu and Yunjiao Li 1987 W-Ti-Re-Sb 88, Proc. of the lst international conference on metallurgy and material science, 2, p. 192

Hughes M A and Hanson C 1983 Proc. symp. hydrometallurgy - research, development and plant practice (eds) Osseo-Asare and Miller (TMS/AIME), pp 491-501

John E Litz 1981 Extractive metallurgy of refractory metals, Proc. symp. (eds) H Y Sohn, Norman Carlson and $J$ Thomas Smith (TMS/AIME), pp 69-81

Ke J J, Yue L D and Liu W D 1986 Hydrometallurgy 16325

Konishi Y, Katada H and Asai S 1986 Metall. Trans. B18 331

Lassner E 1982 Proc. of second international tunysten symposium. San Francisco, p. 71

Li K C $1962 \mathrm{~J}$. Metals 14413

Li K C and Wang Chung Yu 1956 Tungsten (New York: Reinhold Publishing Corporation), 3rd ed. p. 166

MacInnis M B and Kim T K 1983 Handbook of solvent extraction (eds) T C Lo, M H I Baird and C Hanson (New York: John Wiley), p. 689

Marshall R E 1983 Proc. Aust. Inst. Min. Metall. 325

Maslenitsky N N and Perlov P M $1960 \mathrm{Ch}$. in International mineral processing congress 1959 (London: Institution of Mining and Metallurgy), p. 839

Qixiu Z, Bofan G, Welzhuang H and Shaoying H 1988 Research Institute of Non-ferrous Metallurgy, Central-South University of Technology, Changsha, PRC, p. 97

Queneau P and Cooke S R B 1969 TMS-AIME Trans. 2542541

Queneau P B, Huggins D K and Beckstead L W 1981 Extractice metallurgy of refractory metals, Proc, of symp. of the metallurgical society of $A J M E$, p. 237

Shamsuddin M and Sohn H Y 1981 Extractive metallurgy of refractory metals, Proc.symp. TMS/AIME (eds) Sohn, Carlson and Smith, p. 205

Subramanian C, Suri A K and Gupta C K 1992 Trans. The Indian Institute of Metals 45207

Yih S W H and Wang C T 1979 Tungsten (New York: Plenum Press) Ist ed., p. 89

Zhou Ju-Qin and Xue Jian 1990 Proc. of fifth international tungsten symposium, Budapest, p. 79 